\title{
Por que uma Zona de Investigações Poéticas?
}

\author{
Why a Poetic Investigation Zone?
}

¿Por qué una Zona de Investigaciones Poéticas?

Luciano Bedin Costa - Universidade Federal do Rio Grande do Sul | Departamento de Estudos Básicos | Zona de Investigações Poéticas (Grupo CNPq) | Porto Alegre | RS | Brasil. E-mail: bedin.costa@gmail.com | (1) ORc1D

Cristiano Bedin da Costa - Universidade Federal do Rio Grande do Sul | Departamento de Ensino de Currículo | Zona de Investigações Poéticas (Grupo CNPq) | Porto Alegre | RS | Brasil. E-mail: cristianobedindacosta@gmail.com | (1) orci

Marcos da Rocha Oliveira - Universidade Federal do Rio Grande do Sul | Zona de Investigações Poéticas (Grupo CNPq) | Porto Alegre | RS | Brasil. E-mail: marqosoliveira@gmail.com | (1) orci

Alexandre Sobral Loureiro Amorim - UPA 24 horas Hugo Simões Lagranha | Coordenação Médica | Zona de Investigações Poéticas (Grupo CNPq) | Canoas | RS | Brasil. E-mail: amorim.alexandre@yahoo.com.br| (1) orci

Eduardo Guedes Pacheco - Universidade Estadual do Rio Grande do Sul | Programa de Pós-Graduação em Educação - Mestrado Profissional | Zona de Investigações Poéticas (Grupo CNPq) | Osório | RS | Brasil. E-mail: edupandeiro@gmail.com | Đorci

Édio Raniére da Silva - Universidade Federal de Pelotas | Zona de Investigações Poéticas (Grupo CNPq) |Pelotas | RS | Brasil. E-mail: edioraniere @ gmail.com | (1) ORciD

Resumo: Neste ensaio procuramos responder à pergunta "Por que uma Zona de Investigações Poéticas (ZIP)?”, situando-a no contexto político-educacional de nosso país. Trazemos a noção de Zona Autônoma Temporária anunciada por Hakim Bey, compreendendo a poética como um modo de fazer e a política uma forma de viver-junto. Apresentamos a figura da amizade pelo viés pré-individual, não limitando-a à relação entre sujeitos ou às imagens unitárias de Ego e Grupo. Com Agamben e Ortega pensamos a amizade enquanto experiência poética e política, em que os sujeitos são vaporizados de seus lugares de intimidade, forjados e forçados a outras configurações na relação com o mundo e sob circuitos de afetos diversos. Com Dardot e Laval trazemos a noção de cosmocapitalismo como força colonizadora do inconsciente acadêmico, através do que Bordieu chama de homo academicus. Para além de um Grupo de Pesquisa, a ZIP é defendida como território a ser cartografado e como fantasia de convivência.

Palavras-chave: Pesquisa. Poética. Amizade. Homo academicus. 
COSTA, Luciano Bedin; COSTA, Cristiano Bedin da; OLIVEIRA, Marcos da Rocha; AMORIM, Alexandre Sobral Loureiro; PACHECO, Eduardo Guedes; SILVA, Édio Raniére da. Por que uma Zona de Investigações Poéticas?

Abstract: In this essay we attempt to answer the question "Why a Poetic Investigation Zone (PIZ)?", situating it in the politicaleducational context of our country. We introduce the notion of Temporary Autonomous Zone propounded by Hakim Bey, understanding poetics as a way of accomplishment and politics as a manner of living together. We defend the friendship form through the pre-individual tendency, not limiting it to the relationship between subjects or to the unitary images of Ego and Group. With Agamben and Ortega we consider friendship as a poetical and political experience, in which the subjects are vaporized from their places of intimacy, then forged and pushed into other relationship configurations with the world, under circuits of different affects. With Dardot and Laval, we take the notion of cosmocapitalism as a colonizing force of the academic unconscious, by what Bordieu denominated like "homo academicus". Further than a Research Group, the PIZ is claimed as a territory to be mapped also as a fantasy of living together.

Keywords: Research. Poetic. Friendship. Homo academicus.

Resumen: En este ensayo intentamos dar respuesta a la pregunta “¿Por qué una Zona de Investigaciones Poéticas (ZIP)?”, ubicándola en el contexto político-educativo de nuestro país. Traemos la noción de Zona Autónoma Temporal anunciada por Hakim Bey, entendiendo la poética como una forma de hacer y la política como una forma de vivir junto. Presentamos la figura de la amistad a través del sesgo pre individual, no limitándola a la relación entre sujetos ni a las imágenes unitarias de Ego y Grupo. Con Agamben y Ortega pensamos en la amistad como una experiencia poética y política, en la que los sujetos son vaporizados de sus lugares de intimidad, forjados y forzados a otras configuraciones en la relación con el mundo y bajo circuitos de diferentes afectos. Con Dardot \& Laval traemos la noción de cosmocapitalismo como fuerza colonizadora del inconsciente académico, a través de lo que Bordieu llama homo academicus. Además de un Grupo de Investigación, la ZIP es definida como territorio que será cartografiado y como fantasía de convivencia institucional.

Palabras clave: Investigación. Poética. Amistad. Homo academicus. 
Figura 1 - Francis Alÿs - Cuando la fe mueve montañas (2002)

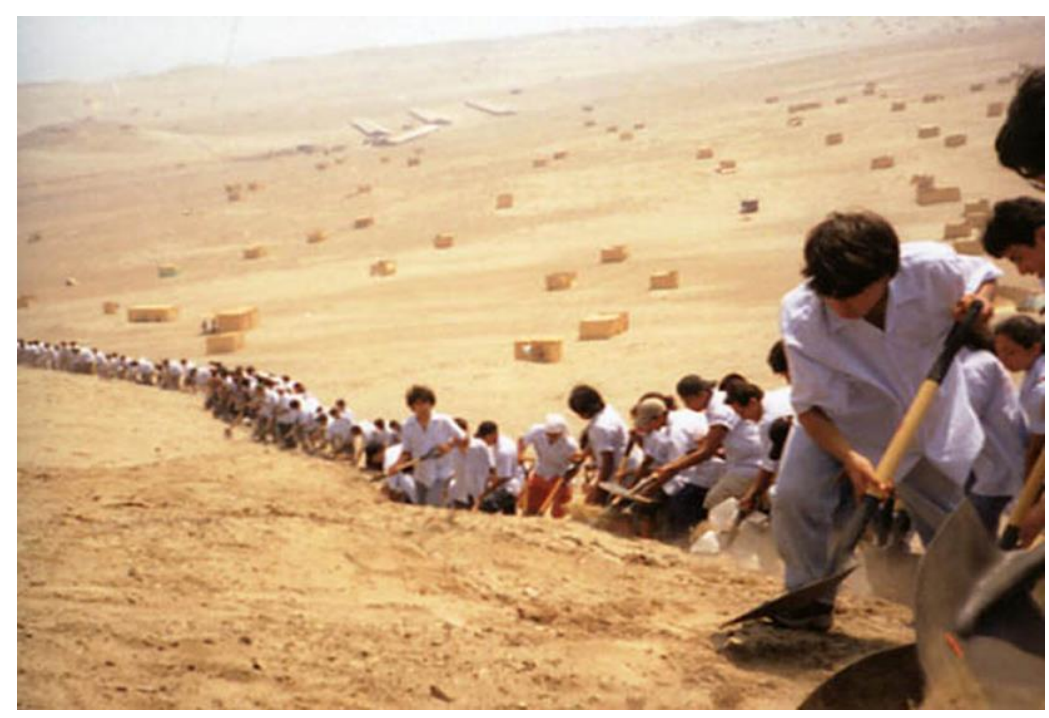

Fonte: ALŸS, Francis. Cuando la fe mueve montañas. Lima, Peru, 2002. Disponível em: https://francisalys.com/when-faith-moves-mountains/. Acesso em: 8 ago. 2020.

A história dos grandes eventos se fez por beijos, mas a do devir dos acontecimentos se faz por abraços. (Diego Marques)

Há os que vencem no amor, há os que vencem na política, há os que vencem na arte. (Fernando Pessoa)

\section{Pré-texto}

Este ensaio foi escrito no rastro dos 145 mil mortos pela Covid-19 no Brasil, dos ataques à autonomia das Universidades Públicas e Institutos Federais, do constante aumento da violência contra as casas de religião afrocentradas e todas as intolerâncias que insistem em atuar no nosso presente. Assim como seus agentes, tais intolerâncias são bem conhecidas. Não nos ocuparemos delas aqui, não reservamos nenhuma linha a eles. Digamos: através desta Zona, não passarão. Questão de estratégia, mas também de sobrevivência. Sabemos por onde andamos, conhecemos bem as barreiras ao nosso pensamento. Este, a seu modo, elege com cuidado sua permeabilidade, ressoa e dá continuidade a linhas que o alimentam, nunca àquelas que pretendem devorá-lo. Escrevemos traçando linhas de vida, e com elas delimitamos espaços nos quais podemos, de fato, nos encontrar. 


\section{ADENTRANDO A ZONA: o poético como lida criativa de luta}

"Máximo esforço, mínimo resultado". Era com esse axioma que Francis Alÿs (2007, [s.p]) definia, em 2002, o propósito articulador de Cuando la fe mueve montañas. Na performance, um grupo de 500 pessoas esforça-se coletivamente para mover em dez centímetros uma imensa duna de areia localizada nos arredores de Lima, Peru. A gratuidade do trabalho, o despropósito da ação e o abismo existente entre o esforço empregado e seus efeitos não sublevam o traço comum que aproxima os voluntários de braços e pás operando em sincronia, sob o sol.

Talvez tenha mesmo chegado a hora de pensar em termos de políticas íntimas, reservadas, quase secretas. Talvez o mover-se imperceptível e efêmero da massa de terra possa nos ensinar algo a respeito daquilo que fazemos ou ao menos podemos fazer juntos, reunidos ao redor de um desejo comum. Talvez a poética, deslocada da materialidade do mundo, possa ser perspectivada em termos de distâncias e proximidades, de sonhos compartilhados em sonos e camas diferentes, de um tipo bastante especial de intimidade.

Um problema de superfícies. Percepções, instaurações e habitações superficiais.

Sabemos que há sempre algo de tênue e mesmo evanescente naquilo que nos propomos aqui discutir. Para abordá-lo, comecemos por definir um meio para o pensamento. Longe de estar circunscrito apenas ao campo das artes e da literatura, entendemos que o gesto poético configura toda e qualquer categoria de ação cuja manifestação é ao mesmo tempo a instauração e o testemunho de um modo de existência a ela vinculado. Nesse sentido, um refrão não é menos que um poema, um verso pode se aproximar de uma performance ou um conceito. Lembremo-nos, desde já, de Paul Valéry (2007, p. 181) e sua disposição a considerar com mais complacência, e até com maior paixão, "a ação que faz do que a coisa feita". A poética, assim, exprime-se pelo fazer, feito uma seta que, por seu próprio ato, converte-se em alvo, recaindo numa relação lúdica e experimental de possibilidades indefinidas.

Para que possamos salvaguardar tanto a especificidade quanto a concretude de nossa matéria, entenderemos tais instaurações como obras de pesquisa e experimentação sensíveis, na medida em que o fragmento de realidade que delas emerge faz com que novas percepções e novos sentidos também se façam possíveis. Ao mesmo tempo, reservaremos o nome Zona de Investigações Poéticas (ZIP) aos movimentos que realizamos juntos, enquanto grupo. Trata-se de uma assinatura, não de uma demarcação de propriedade. De fato, é em meio a incontáveis outras 
investigações poéticas, atualizadas em tempos e espaços outros que delimitamos a singularidade de uma Zona particular. A ZIP, então, é apenas uma forma de nomear o nosso viver-junto, nosso criar-coletivo, nosso lema comum.

Para nós, uma ZIP possui um triplo-sentido-posto-em-dobra: (1) ao mesmo tempo em que é um Grupo de Pesquisa, (2) é também um território a ser cartografado e (3) uma fantasia de convivência. Sobre o Grupo de Pesquisa falaremos pouco, ou quase nada. Interessa-nos apenas dizer que foi constituído em 2017, está cadastrado do diretório CNPq, reúne docentes e pesquisadores vinculados à Universidade Federal do Rio Grande do Sul (UFRGS), à Universidade Federal de Pelotas (UFPEL) e à Universidade Estadual do Rio Grande do Sul (UERGS), tendo como propósito o fomento de práticas investigativas na intersecção entre Educação, Psicologia, Filosofia, Artes e Literatura. As dimensões cartográfica e relacional são entendidas como pedacinhos de utopia (BARTHES, 2004), uma espécie de indireto que se desprende das amarras institucionais, agindo de modo autônomo e independente a elas. É dessas duas dimensões que iremos nos ocupar a seguir. Para tanto, o território será pensado como uma superfície relacional onde "falo em vez de morrer" - "o que quer dizer que falo neste lugar onde se morre" (BLANCHOT, 2001, p. 127) e a convivência como amizade - em sua dimensão de infinidade (que comporta o máximo de estranheza compossível), mais que de afinidade ingênua (que transporta os abraços ao enlace de si mesmo).

\section{NA ZONA: cartografando superfícies relacionais e porquês}

Às vezes fazer algo poético pode se tornar políticoe às vezes fazer algo político pode se tornar poético (ALŸS, 2007).

\section{Porque há sempre algo entre}

A poética como entusiasmo criador, inspiração ou atração pelo diverso, diferença em produção. A prática política, implicada no rompimento com a lógica dos totalitarismos, enquanto possibilidade, transformação. Criada e recriada constantemente, ela é criação viva, em ato, isto é: poiesis, ação de inventar, produzir, criar possíveis. Uma dimensão poética da ação política, sua prática, seja onde for, como "aquilo que arrasta a língua para fora de seus sulcos costumeiros, leva-a a delirar" (DELEUZE, 1997, p. 9). E, assim imbricadas, "como dois lutadores que não podem mais derrotar um ao outro, e deslizam numa linha de declive" (DELEUZE; GUATTARI, 
1997b, p. 113), não havendo como separá-las, identificamos que tantas são as regiões fronteiriças entre elas que só nos resta acoplar estes termos, tanto quanto já se acoplam suas manifestações.

Para nós, a imagem de uma ZIP reserva inspiração direta na Zona Autônoma Temporária (TAZ) anunciada por Hakim Bey, "uma espécie de rebelião que não confronta o Estado diretamente, uma operação de guerrilha que libera uma área (de terra, de tempo, de imaginação) e se dissolve para se refazer em outro lugar e outro momento, antes que o Estado possa esmagá-la" (BEY, 2010, p. 32). Assim como em uma TAZ, a ZIP compreende a poética como um "modo de operar" e a política enquanto "forma de viver junto" (BEY, 2010, p. 143), abraçando processos co-criacionais em meio a relações de abertura e fechamento de mundos. Sua zona de existência é um espaço-tempo de ensaio, ou melhor, uma série contínua de ensaios, sugestões, tentativas, manifestações concretas de uma fantasia poética.

A morfologia dinâmica de uma ZIP responde apenas aos movimentos do sentido que nela são agenciados. Mais precisamente, a extensão de seu território compreende a distância sensível entre aquilo que se sabe e o que torna-se possível saber coletivamente. Desse modo, entendemos a ZIP como uma ocasião para - ao menos - três aprendizagens complementares, vinculadas a três posturas específicas, a saber: experimentar com o que não se conhece, ou então relacionar-se de modo inédito com o já conhecido; estabelecer relações ainda não estabelecidas com os sujeitos e os materiais em circulação na Zona; testemunhar e legitimar perspectivas originais de existência. Tais mudanças de estado dizem respeito à totalidade das relações em uma ZIP, e é por elas que seus atores são pensados. Em cada Zona instaurada, a mesma "prontidão à experiência de um encontro com uma alteridade sempre movente e, portanto, em estado de recomposição constante" (AQUINO, 2014, p. 175).

Criação de encontros, estabelecimento de superfícies de contato, a produção de alguma porosidade. Uma ZIP é sempre um caso de partilha, e toda partilha é um problema comum.

Entre é a discreta palavra que perpassa todos esses encontros. Em uma ZIP, um corpo nunca é apenas um objeto ou imagem que se projeta para a identificação dos demais, mas sim um corpo entre corpos, de modo que essa espécie de corporeidade compartilhada sugere uma "ética de intimidade e reciprocidade mais do que alienação e agressão" (FOSTER, 2017, p. 206). Sejamos ainda mais precisos: a ZIP acontece apenas entre, "precisamente porque pensar, sofrer ou amar implicam um corpo rodeado, e não só, implicam também: um corpo que rodeia" (TAVARES, 2013, p. 189). Seja onde for, é sempre a heterogeneidade - de origens, destinos e 
códigos culturais; de idades, tempos, fôlegos e motivos; de atenção e interesse; de vozes, níveis, perfis, gêneros, gostos e humores - o que constitui a superfície de uma ZIP e sua política de fricções.

\section{Porque diante da boca do tigre resistimos com delicadeza e amor}

ESPANTO: Desconcerto Quando alguém Faz planos E, de repente, Vem montanhas (BRISANT, 2018, p. 36).

Há 30 anos, quando colocávamos a faixa 2 do disco "Jesus não tem dentes no país dos banguelas", escutávamos os Titãs tocando o que viria a se tornar um slogan em nossas futuras militâncias: “A gente não quer só comida / A gente quer comida, diversão e arte / A gente não quer só comida / A gente quer saída para qualquer parte” (ANTUNES; FROMER; BRITTO, 1987). Embora tenhamos atingido certo consenso em relação aos dois primeiros versos da música - de que desejamos mais do que a sobrevivência -, pode ainda parecer provocador pensar a arte (que aqui defendemos enquanto gesto poético) como experiência de saída (a alguma ou a qualquer parte), o que não significa de modo algum um escapismo estético ou uma debandada política. Ao exigirmos de nossos gestos poéticos uma saída, ou uma saída aos nossos gestos poéticos (considerando os múltiplos territórios que habitamos e as políticas públicas a estes agregadas), não estamos com isso querendo escapar ou debandar das lutas que se atualizam em nossos espaços. É o contrário, queremos agregar às lutas, aos movimentos e ações que têm na busca por maior equilíbrio social, a força poética. Nosso convite passa pelo entendimento e pela necessidade de que tais lutas possam acontecer através do agenciamento de outras formas de enfrentamento, de resistência. Por isso, não é uma questão de substituir um caminho pelo outro, mas, sim, trazer para a cena de confronto a poética como arma para o enfrentamento daquilo e daqueles que, teimosamente, ao longo da história, têm feito excluir a diferença do contexto do viver.

Embora admitamos que, diante da violência é preciso agir com certa contundência, uma ZIP nos incita a olhar os dentes do tigre do presente para ali (nos) localizarmos desde a fragilidade, revelando-se uma outra forma de resistência. Aqui, estamos nos referindo ao belíssimo dossiê da Revista Cult, intitulado "Quando a delicadeza é uma afronta", organizado pelo poeta Tarso de Melo (2019), em que traz uma série de poetas contemporâneos que atendem à provocação do título em questão. 
Se, por um lado, aplaudo o vigor com que poetas do nosso tempo têm reagido sem rodeios, aos desafios e ataques que a democracia vem sofrendo neste país, por outro me anima perceber que, ao expor algumas "fragilidades" que, sob um olhar distraído, nada parecem dizer sobre a violência que nos cerca, se revela uma outra forma de resistência e de afronta a tudo que pretende soterrar nossa vontade de viver (MELO, 2019, p. 4).

Em Porque esperamos [notas sobre a docência, a obsolescência e o vírus] (COSTA; MUNHOZ; LULKIN, 2020), livro editado pelo selo editorial Autonomaz ${ }^{1}$, somos interpelados pelo poema coletivo “(a senha é amor)” (SANT’ANNA JUNIOR et al., 2020, p. 60-66), assinado por 23 autoras e autores vinculada(o)s a programas de Pós-Graduação da Universidade Federal do Rio Grande do Sul - UFRGS. Em meio à pandemia da Covid-19, em que presenciamos milhares de vidas ceifadas pela imobilidade das políticas de enfrentamento, somos convocados a agir desde nossas presenças amorosas. De revés ao descaso, subnotificação e obscurecimento informativo protagonizados pela boca do tigre do governo federal, lançamos nossas ZIP nas surdinas da delicadeza em uma topografia amorosa mas não menos combatente.

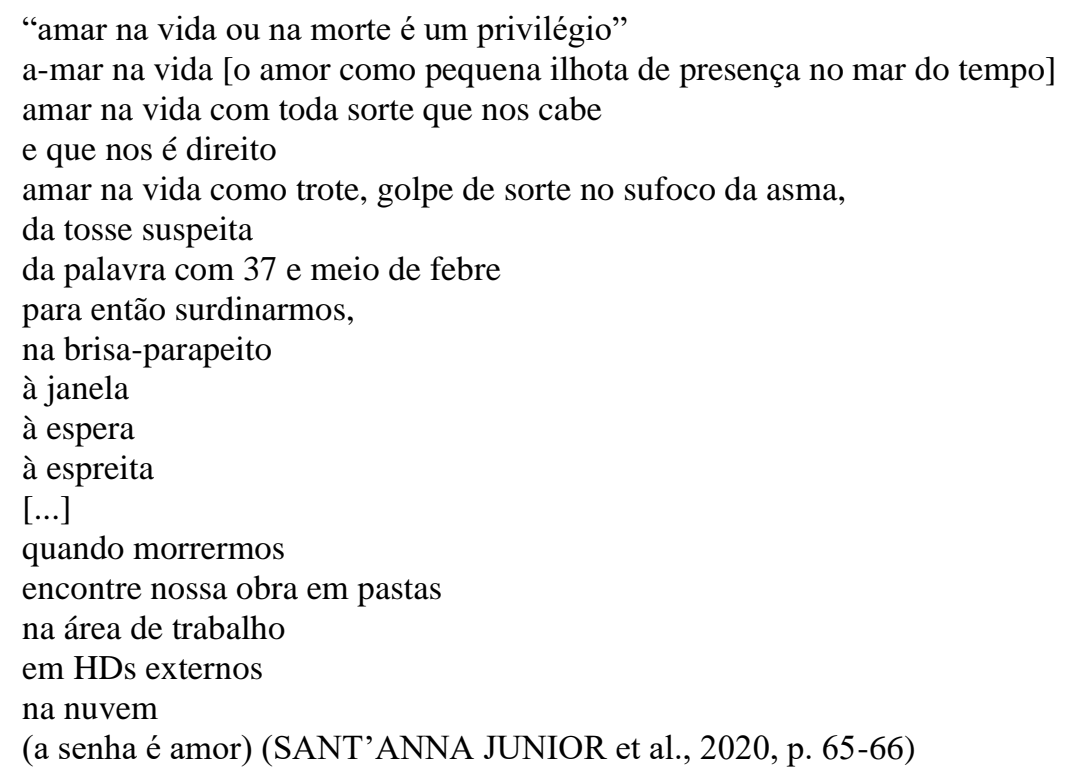

\section{Porque são necessários novos corpos a partir de outros circuitos de afetos}

Há de se insistir que nunca seremos capazes de pensar novos sujeitos políticos sem nos perguntarmos inicialmente sobre como produzir outros corpos. Não será com os mesmos corpos construídos por afetos que até agora sedimentaram nossa subserviência que seremos capazes de criar realidades políticas ainda impensadas (SAFATLE, 2016, p. $37)$.

1 Autonomaz é um selo editorial criado pelo Grupo de Pesquisa CNPq Zona de Investigações Poéticas (ZIP), destinado à publicação de textos acadêmicos, poesia e materiais artísticos na fronteira entre educação, filosofia, psicologia social e artes. 
Na perspectiva de uma ZIP, toda amizade é potencialmente política. Em sua dimensão molar - em que as forças cedem lugar à formas (estando os sujeitos a estas alocados) -, a amizade encontra sua via possível na imagem da aliança. Na aliança cintilam os sujeitos e suas instituições, assim como seus projetos, pactos, utopias, sonhos, segredos, neuroses, mazelas e interditos. Na aliança, que em sua dimensão acadêmica-institucional atende também pelos nomes de grupo, núcleo ou laboratório, os sujeitos circulam e estabelecem interações produtivas (ou não) situados a partir de determinadas hierarquias e relações de poder. No entanto, ainda que entendamos como necessária certa estratificação institucional, uma ZIP não se reduz à mesma. Se, por um lado, os sujeitos se deslocam segundo determinadas posições - de coordenador(a), pesquisador(a), orientador(a), orientando(a), professor(a), estudante, bolsista -, por outro, há todo um "circuito dos afetos" (SAFATLE, 2016) capaz de agenciar a repetição como também de mobilizar a diferença.

Uma ZIP interessa-se por novos corpos agenciados a partir de outros circuitos afetivos, entendendo que a adesão coletiva a determinados estratos se faz à luz e sombra de afetos específicos e difusos, muitos destes mapeáveis e suscetíveis ao exercício de nossas cartografias. Circuitos afetivos marcados pelo medo produzem corpos paranoicos. Circuitos melancólicos fabricam corpos consternados. Uma ZIP concebe a fabricação e também o desmanchamento destes corpos enquanto atividade poética, compreendendo que a privatização dos afetos em circuitos individualistas não é uma boa estratégia para abertura de novos mapas. A cartografia de uma ZIP atua na sobreposição de mapas em que linhas contornadas pelos estratos - as quais, segundo Costa e Amorim (2019), contém e organizam fluxos dispersivos de desejo em regimes e padrões administráveis - se veem confrontadas a limites flutuantes e imprevisíveis, nos encontros com as dobras de um 'fora' com o qual se conectam, se ativam e se transformam. Nesse contexto, uma investigação poética é sempre uma investigação dos limites e limiares das formas, sejam estas obras de arte, sujeitos, grupos ou mesmo instituições. Em outras palavras, dizemos que uma ZIP leva consigo o que Hakim Bey chama de "estética da fronteira", o acontecimento que se dá "entre o caos e a ordem, a margem, a área da 'catástrofe', onde o desmoronamento do sistema pode significar sua iluminação" (2010, p. 92). Na hidráulica dos fluxos institucionais, o afrouxamento de uma simples junta afetiva pode ser capaz de arremessar sujeitos e grupos a processos inéditos e, não raramente, incontornáveis. 


\section{Porque para um novo corpo é necessário uma língua que o favoreça}

Não há um esperanto da revolta. Não são os rebeldes que devem aprender a falar anarquista, mas os anarquistas que devem se tornar poliglotas (COMITÊ INVISÍVEL, 2016, p. 277).

Concordamos com o Comitê Invisível quando diz que "a linguagem, longe de servir para descrever o mundo, ajuda-nos sobretudo a construir um” (2016, p. 54). Na dimensão de uma ZIP cuidemos para que nossos corpos não caminhem somente em esteiras linguísticas, estas que demandam nossos maiores esforços mas que não nos fazem sair do lugar. Uma vez em uma ZIP, os corpos precisam de uma língua que os favoreça. E não é à toa que grandes gestos poéticos da história fizeram uso de línguas que lhes eram próprias (utilizamos aqui o adjetivo grande para marcar uma expressividade social, mesmo sabendo que no domínio operacional uma operação poética se dá sempre em uma zona menor). Lembremos então de Guy Debord e a Internacional Situacionista, mais especificamente o Questionário de 2 de dezembro de 1958: "Se você não é situacionista, diga sucintamente o que o impede de sê-lo" (INTERNACIONAL SITUACIONISTA, 1958 apud JACQUES, 2003, p. 86). Lembramos também de Caranguejos com cérebro, o primeiro manifesto Manguebeat, publicado em 1992, em que apresenta, sob a superfície linguística do mangue, o nascimento do que chamará de mangueboys e manguegirls.

Os mangueboys e manguegirls são indivíduos interessados em: Teoria do Caos, World Music, Legislação sobre meios de comunicação, Conflitos Étnicos, Hip Hop, Acaso, Bezerra da Silva, Realidade Virtual, Sexo, Design, Violência e todos os avanços da Química aplicada no terreno da alteração / expansão da consciência (QUATRO; SCIENCE, 2013, [s. p]).

Encontramos nos Situacionistas, no Manguebeat e em tantos outros movimentos poéticos o gesto de fundação de uma língua, a que Roland Barthes (2005), inspirado em Marquês de Sade, Ignácio de Loyola e Charles Fourier, chamou de logoteta.

A língua que fundam não é, evidentemente, uma língua linguística, uma língua de comunicação. É uma língua nova, atravessada pela língua natural (ou que a atravessa) [...]. Isso não impede essa língua artificial [...] de seguir em parte as vias de constituição da língua natural (BARTHES, 2005, p. 10).

Para mostrar a importância de uma nova língua na constituição de Zonas Autônomas Temporárias (TAZ), Hakim Bey retoma a figura do logoteta situando-o enquanto um "construtor de sistemas menores" e de "criador mundos feitos de palavras" (BEY, 2010, p. 18). Como em uma TAZ, uma ZIP aposta em línguas menores capazes de resistir criativamente diante da 
veneração frenética à comunicação a todo custo e direito. A operação logoteta de uma ZIP distancia-se da ecolalia de determinadas militâncias que, ao enunciarem a si mesmas, circunscrevem toda uma paisagem sobre a qual precisarão empreender esforços para dobrá-la. Lembramos da crítica que o Comitê Invisível faz a militâncias calcadas na ideia de aliança, estas que, sob a mirada de um inimigo, apertam o tubo da linguagem de modo que o sujeito-que-sequer saia dali (sempre constrangido): "Quem está do lado dos canalhas? Quem não se arrisca? Quem se coloca em risco por aquilo em que acredita? Até onde o partido adversário se permite avançar? Ele recua perante o quê? Está apoiado sobre o quê?” (COMITÊ INVISÍVEL, 2016, p. 273-274). É Blanchot (2001, p. 116) quem parece nos oferecer uma boa pista para pensar duplicidade inconciliável que há entre esta "palavra de poder", que "quer ser tudo", e a "palavra fora do confronto", que "fala antes de tudo e fora de tudo", palavra essencialmente poética e, como tal, destinada a qualquer serventia (inclusive às capturas do próprio poder). Embora nunca saiba de antemão com quais palavras irá avançar (a escrita deste ensaio é uma prova viva disso), uma ZIP ao menos sabe que se trata de "Nomear o possível, responder ao impossível" (BLANCHOT, 2001, p. 117).

\title{
NA ZONA: a amizade infinita
}

\section{Porque apostamos na política da amizade como amor mundi}

\begin{abstract}
A solidão mórbida não é melhor que o consenso manipulado - na verdade ambos não passam de diferentes lados da mesma moeda: o falso individualismo versus o falso coletivismo (BEY, 2010, p. 22).
\end{abstract}

Ao compreender a política como uma forma de viver junto (BEY, 2010, p. 143), uma ZIP atenta ao que Blanchot (2010, p. 215) tão bem designou como "desvio em direção à simplicidade". O simples, neste sentido, não nos parece propriamente o vínculo de amizade entre os sujeitos envolvidos numa ZIP (dado que a amizade existe como um elemento a priori, ou mesmo enquanto condição), mas a sua conjugação em práticas investigativas menores que, valendo-se da amizade, jogam o coletivo a regiões individualmente impensáveis. No ensaio Por uma ética $e$ uma política da amizade, Ortega (2020) nos traz algumas pistas interessantes para pensarmos a amizade enquanto experiência estética e política, dado que, na amizade, os sujeitos são vaporizados de seus lugares de intimidade, forjados e forçados a outras configurações na relação com o mundo. A crítica de Ortega se dá pelo viés do que chama de "tirania da intimidade" (2020, 
p. 4), a qual exige que os agenciamentos coletivos se submetam ao crivo e juízo das individualidades envolvidas, como se estas fossem o ponto de partida e o local de chegada.

Como parar a máquina governamental em que parece ter se transformado toda a política, e ter acesso a uma nova política, uma política da amizade, calcada em uma outra experiência do tempo e capaz de nos expor às exigências do compartilhamento das existências das quais não podemos nos esquivar? (SCRAMIM, HONESKO, 2009, p. $11)$.

Pensar a amizade como experiência política, e não necessariamente íntima, nos convoca ao redirecionamento dos vetores a ela e por ela implicados. Ao invés de um circuito fechado em que duas individualidades amigas que se inter-afetam, a amizade enquanto política se desdobra a partir de redemoinhos, de espirais que, ao ganharem relação entre os corpos envolvidos, jogam estes mesmos corpos para uma zona que lhes é exterior.

Figura 2 - ZIP, Amizade infinita (2020)
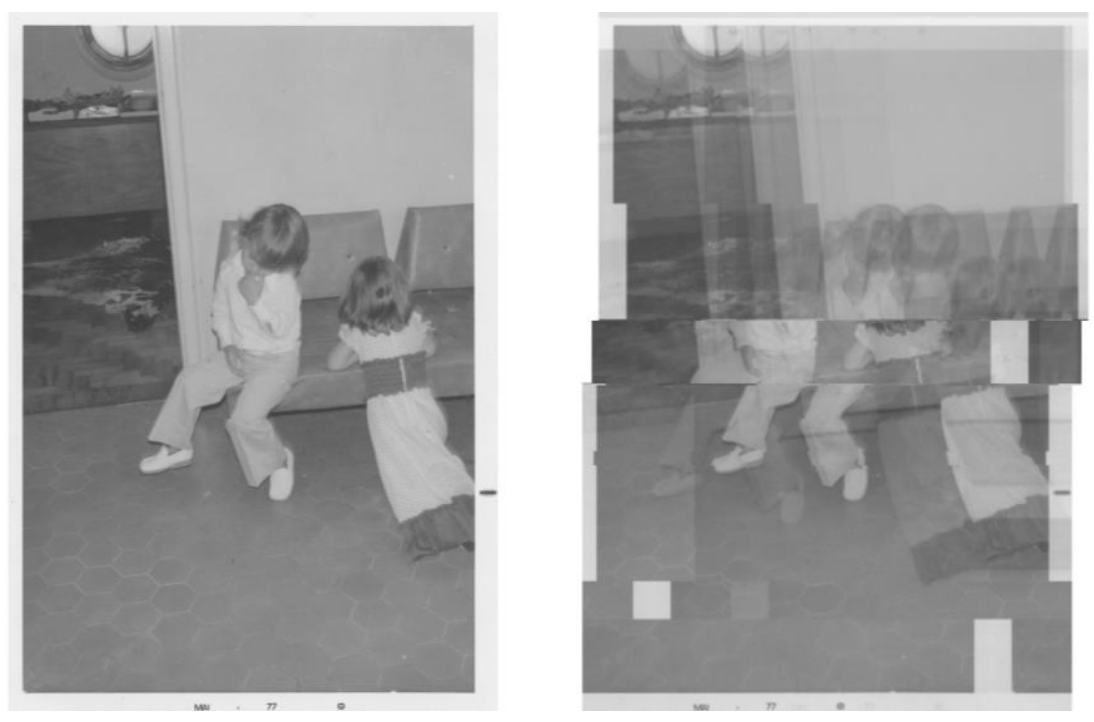

Fonte: Arquivo pessoal dos autores.

A inversão dos vetores pela amizade implica em uma saída de mundo (e não do mundo), espécie de amor mundi, "esticador de horizontes" (BARROS, 2010, p. 322). Falamos da amizade como prerrogativa de uma zona que excede os amigos que dela fazem parte.

Em seu ensaio "O amigo", Agamben nos traz a amizade enquanto experiência ontológica e política, entrelaçando, em um mesmo abraço, a dimensão do ser e de seu devir na relação com o outro. “A amizade é a instância desse com-sentimento da existência do amigo no sentimento da 
existência própria [...]. A sensação do ser é, de fato, já sempre dividida e com-dividida, e a amizade nomeia essa com-divisão" (AGAMBEN, 2009, p. 89).

Não se trata, portanto, de uma zona que abriga apenas sujeitos. Certamente o grupo está constituído por pessoas, cada uma delas com seu trabalho, suas paixões, seu corpo. Não negamos a importância destas em uma ZIP. Mas, num certo sentido, seria preciso avançar para compreender a zona como uma hecceidade (DELEUZE; GUATTARI, 1995) ${ }^{2}$, um momento escuro, difícil de precisar, em que os seus integrantes deixam de ser sujeitos e aparecem uns aos outros como puro acontecimento.

É o próprio lobo, ou o cavalo, ou a criança que param de ser sujeitos para se tornarem acontecimentos em agenciamentos que não se separam de uma hora, de uma estação, de uma atmosfera, de um ar, de uma vida. A rua compõe-se com o cavalo, como o rato que agoniza compõe-se com o ar, e o bicho e a lua cheia se compõem juntos (DELEUZE; GUATTARI, 1997b, p. 50).

Parece haver neste acontecimento algo que ultrapassa a relação entre os sujeitos que compõe uma ZIP. Contudo, se os sujeitos não são o centro desta Zona de Investigações Poéticas, o que estaria disparando tais acontecimentos? Se tais ações não têm sua origem nas pessoas que articularam o grupo, então como elas operam? A hipótese que apresentamos é a de um sistema metaestável, onde singularidades pré-individuais pululam em busca de soluções para esta ou aquela problemática (SIMONDON, 2020). Seria possível situar esse campo? Talvez em algum sentido seja o poético. Para além das investigações poéticas realizadas pelos integrantes de uma ZIP há também um poético enquanto individuação, hecceidade. Tal qual o bicho que se mistura com a lua cheia; tal qual a hora terrível - cinco horas da tarde - tal qual o vento frio nesse extremo sul do Brasil, o poético, aqui, pode ser pensado como um processo de individuação. E se como sugerem Deleuze e Guattari (1997b) “somos todos cinco horas da tarde”, talvez a individuação deste poético seja algo a forçar a produção de uma ZIP.

\section{Porque mesmo em grupo há um ego à espreita no homo academicus}

Em nossa experiência (e digo não simplesmente em especulações intelectuais, mas sim na vida cotidiana) nós percebemos que o "Ego" pode chegar a ser tão espectral como o "Grupo" - ou aliás, tão fantasmagórico como qualquer abstração capaz de controlar a conduta, o pensamento ou o destino (BEY, 2010, p. 11).

\footnotetext{
${ }^{2}$ Estamos tomando hecceidade, aqui, como “individuação sem sujeito”. Essa fórmula é apresentada por Deleuze e Guattari no "Prefácio para Edição Italiana", publicado no primeiro volume da edição brasileira de Mil Platôs: capitalismo e esquizofrenia e desenvolvida de modo mais amplo no capítulo Devir-Intenso, Devir-Animal, Devir-Imperceptível do volume quatro da mesma obra/edição.
} 
Ao tentar funcionar como uma TAZ, a ZIP "rechaça o falso transe do grupo como espetáculo, como também a inefetividade solitária do ermitão amargurado" (BEY, 2010, p. 12). Na dimensão do homo academicus, instigante imagem criada por Bordieu (2011), percebemos a cintilação destes dois imaginários: (1) seja na atomização das coletividades nômades em prol de um nome, de um lema, de uma sigla de constrangimento - nas placas dos gabinetes universitários pululam os nomes de núcleos, laboratórios e grupos, verdadeiros estandartes demarcadores de território e indicadores dos modos de ali funcionar; (2) seja no próprio agir da pesquisa concentrada na figura do pesquisador que, encerrado em seu gabinete e sob a sombra de sua biblioteca pessoal, escreve artigos, redige pareceres, corrige provas, bebe vinho, farfalha polêmicas, etc. $\mathrm{O}$ conjunto destes dois imaginários reforça a tese de que, mesmo em grupo, o homo academicus funciona sob a lógica do ego isolado, "reduzido a um terminal de comunicações, um funil de mercadorias e fetiches" (BEY, 2010, p. 12).

Contudo, é importante que localizemos o homo academicus dentro de uma lógica maior e que parece inclusive uma das causadoras de seu próprio surgimento. Trazemos aqui o que Dardot e Laval (2017, p. 12) chamam de cosmocapitalismo, um sistema de normas que se apropria das atividades do trabalho, dos comportamentos e das próprias mentes, estabelecendo uma concorrência generalizada, regulando a atividade do indivíduo consigo mesmo e com os outros segundo a lógica da superação e do desempenho infinitos. O homo academicus hiperprodutivo, um pesquisador do colapso positivo, poderíamos dizer com Han (2017), das métricas avaliativas e dos altos percentuais de impacto ou engajamento, faz tudo atuar a sua "imagem e semelhança, e não faz mais do que replicar, materializar, intensificar e estender à toda a população" imagética que recobre "as formas dominantes de gestão biopolítica e necropolítica que já estavam trabalhando sobre o território" (PRECIADO, 2020, p. 5).

Assentado no imaginário transparente de um grupo que se quer positivo e bem avaliado pelas políticas de Estado, o homo academicus toma para si a figura de um nós tornando possível a presença da figura do outro (este encarnado como sujeito ou mesmo como um grupo), o qual será tomado como: (1) um possível aliado para capitalizar citações e publicações; (2) um iminente inimigo a disputar a ressonância métrica do impacto de suas produções; ou (3) qualquer coisa indiferente. Atualiza-se a lógica existencialista de que o inferno são os outros, de que o outro representa o cerceamento das liberdades individuais, em um jogo em que o suposto prisioneiro foge em direção ao seu próprio rabo e, mais que isso, força-se até o limite de suas forças 
produtivas: esgota-se em uma positividade do igual, escreve e vive em tristeza. Tirita mesmo na ávida chama: "Então, isto é que é o inferno? Nunca imaginei... Não se lembram? O enxofre, a fogueira, a grelha... Que brincadeira! Nada de grelha. O inferno... são os outros" (SARTRE, 2006, p. 107).

$\mathrm{Na}$ zona, talvez, preferiríamos estar situados na indiferença de uma coisa qualquer, frutos de uma negligência essencial que despista o homo academicus, encerrado em seu claustro intelectual, e escrever nossa sigla errante como o homo quotidianus de Blanchot (2007): tendendo menos para a fala analítica e mais para a fala cotidiana (mesmo confinados, pertencemos às ruas, armamos coletividades errantes, grafamos anonimamente as superfícies do mundo). Se contamos com as métricas, claro, é para armar a graça e descobrir novas maneiras de errar juntos.

Assim, unidos por uma questão de infinidade (não determinada, mas indeterminante) a zona cotidiana de investigação e docência remete a um outro sem referência ao Uno ou ao Mesmo (e o nosso inferno e rabo passa ser non serviam). Não se trata somente de "proximidade, proximidade de luta, de serviços, de essência, de conhecimento ou reconhecimento, talvez até de solidão, é a estranheza entre nós" que se caracteriza como uma "interrupção escapando a toda medida" (BLANCHOT, 2001, p. 121-122). Enquanto zona de investigação poética, origina-se no espaço-tempo da linguagem, “aí onde esta, pela escrita, derrota a ideia de origem” (BLANCHOT, 2001, p. 126).

Sabemos bem que na superfície dos fatos do homo academicus podemos ler conjuntos de relações. Aquelas, digamos, do primeiro tipo, trabalham para tornar aquilo que lhes é alheio idêntico, fazendo da afirmação de conjunto a única verdade: o próprio homo academicus, cheio de si. As relações de segundo tipo, obtêm imediatamente a unidade por coincidência e participação, e são obtidas pela imediação - no grupo de tal ordem as singularidades perdem-se: o homo academicus, agora, a contemplar-se em uma sala de espelhos, onde "há êxtase, fusão, fruição" (BLANCHOT, 2001, p.119). Mas, voltamos, ao constituir-se em uma zona cuja superfície impele o investigador e escritor para as ruas (do confinamento do gabinete para o solo que corre), as relações que se estabelecem podem ser aproximadas àquelas que Blanchot chamou de terceiro tipo: o "Outro me fala e é tão somente esta exigência de palavra", "relação daquilo que permanece radicalmente separado", que "se inscreve na palavra, não é uma relação transubjetiva ou intersubjetiva, mas inaugura uma relação que não seria de sujeito a sujeito nem de sujeito a objeto" (BLANCHOT, 2001, p. 123). O homo academicus desliza para fora e perde 
seu eu, seu outro de estimação e seu gênero tacanha. Trata-se de um corpo que, apenas, traduz as relações que o atravessam no desejo de escrever "infinitivamente".

\section{Porque uma zona é trincheira para bandos}

Os bandos, humanos e animais proliferam com os contágios, as epidemias, os campos de batalha e as catástrofes (DELEUZE; GUATTARI, 1997a, p. 23).

Na dobra Deleuze-Guattari-Bey acolhemos a conformação de bando como um arranjo estratégico que nos interessa. A subjetividade deriva dos movimentos inusitados que (in)surgem do arranjar-se em bando (com) desejos, rompendo com a perspectiva de lógicas ordenadoras ou totalizantes. Afinal, a zona permite então aos grupos (ou grupelhos) moverem-se como "um bando, uma população, um povoamento, em suma, [...] uma multiplicidade” (DELEUZE; GUATTARI, 1997b, p. 19) e nestes movimentos pensar seus próprios fazeres como dispositivos potenciais de escape e captura, deslizando diretamente contra as forças estatais neutralizadoras, mas também (e principalmente) na produção da própria zona (seu espaço gerador), como brecha para subversões, motins e indisciplinas - e tudo mais - que possa promover linhas de fuga mesmo que momentâneas. Nestas dobras, traçando estes vetores normalizadores de bando, a zona tornase então trincheira - espaço de resistência e criação - e partir do bando está composta uma máquina-de-guerra. Esta responde então "à questão da ambiguidade da "linha de fuga" (que consiste menos em fugir de uma situação do que em "fazê-la fugir", em explorar as pontas de desterritorialização" (ZOURABICHVILI, 2004, p. 33). Os bandos então, passando a funcionar como máquinas-de-guerra, procedem por rizoma, opostos assim às estruturas arborescentes identificadas com o Estado. "Invenções de máquinas de guerra, irredutíveis aos aparelhos de dominação e às soberanias hierárquicas. Necessárias à invenção guerreira de si" (CARNEIRO, 2007, p. 219) e destarte, para além de um grupo de pesquisa, a cartografia de uma zona pode instaurar um "bando de pesquisa". Quando inscritos em um bando, que se movimenta sem tentar prever o comportamento exato e determinado de cada trajetória, seus componentes dificilmente serão coagidos por trajetórias regulares, linhas retas, estabilizadas em equilíbrio. O bando não almeja a revolução, mas o levante, posto que este "é como um bacanal que escapou - ou foi forçado a desaparecer - de seu intervalo intercalado e agora está livre para aparecer em qualquer lugar ou a qualquer hora" (BEY, 2010, p. 40). Assim, a máquina-de-guerra bando comporta em si a poética política e com ela procede não se assentando em certezas, como nas leis deterministas, 
mas movendo-se sobre possibilidades e criando brechas, e assim faz seus combates. A poesia carrega consigo desejos de composição (e decomposição) de territórios, incitando linhas de fuga. O bando, ocupando a (e ocupado da) política a partir da poética, combate estrategicamente como máquina de guerra. A ZIP assim, "faz valer um furor contra a medida, uma celeridade contra a gravidade, um segredo contra o público, uma potência contra a soberania, uma máquina contra o aparelho" (DELEUZE; GUATTARI, 1997a, p. 13), e tateando os rastros das batalhas travadas e por travar, sobram-nos, como escombros de nossas palavras, os porquês.

\section{DEIXANDO A ZONA: porque deve haver algo entre o não dá pra fazer nada e o fazer o que dá}

De resto, o que não se estrutura como um Estado, como uma organização, só pode ser disperso e fragmentário e encontrar, em seu caráter de constelação, a própria matéria para sua expansão. Cabe a nós, portanto, organizar o encontro, a circulação, a compreensão e a conspiração entre as consistências locais. A tarefa revolucionária se tornou em parte uma tarefa de tradução (COMITÊ INVISÍVEL, 2016, p. 277).

Antes de sairmos, lembremos uma vez mais porque entramos nessa. Porque escrevemos não-passeatas e não chutamos cabeças, pasmamos com todo o corpo diante do encontro com nossa solidão. Porque não escrevemos manifestos. Escrevemos nós mesmos. Por que escrevemos nós mesmos, nos manifestamos. Porque há uma poética do sonho, como as há das diversas realidades. Porque estamos rodeados por montanhas interiores, tão imensas e desérticas quanto aquelas que nos roubam horizontes. Porque citamos como gesto político em desassossego, com uma criança pobre que para de correr. Porque traduzimos como poética a nossa zona de combate. Porque o sossego não é a ficção encarnada da nossa pedagogia e cá não estaremos, nunca, sós ou cegos. Porque absurdamos a vida ao som de nossas letras. Porque investigações permitem serem pensadas (e produzidas) menos como inquéritos procuradores de respostas e mais como pesquisariar (um pesquisar de quem para escrever-e-pensar compõe artesanias). Porque deseducamos ao nosso balanço. Porque preferimos não fazer do estar junto um espetáculo e não fazemos o tipo amargurado que prefere a solitária caravana de si. Porque sabotamos todo circuito de afetos capazes de subnutrir os desejos e paralisar as ações. Porque nos reunimos para tentar, como condição de uma fantasia poética temporária. Porque afirmamos o que podemos, só. Porque rasuramos a nossa ilusão biográfica como loucos de cara que colecionam letras alheias e sacolinhas. Porque interessa-nos o movimentar-se para além do já-colocado-estável-seguro-eprevisível. Porque nos seduz o inusitado, o imprevisto, o improviso. Porque estamos sempre 
disponíveis para sermos arrebatados pelos acontecimentos. Porque o verbo clarear é insuficiente. Porque a poética desafina, dissona. Porque a poética é criação, e criar é produzir espaços-tempos de liberdade. Porque compartilhamos uma certa responsabilidade feliz de resistência. Porque criase para resistir ao sistema. Porque cria-se para não morrer. Porque temos mangue nas veias que riscam nossas zonas. E tambores e rap e som e fúria que vibram em suas superfícies. Porque somos comuns e pertencemos ao povo-inventa-línguas. Porque as fabulações são mais defensáveis que as verdades inequívocas. Porque os procedimentos nos interessam mais que as metodologias. Porque dispersamos e fragmentamos todo o Estado que há em cada um de nós ao sobrescrevermos as marcas do texto. Porque o escrever junto transforma mundos. Porque riscamos a capa do livro para conspirar o prazer da aula. Porque os rigores que levamos em conta são apenas os éticos, estéticos e políticos. Porque nomeamos crápulas e privilégios e escrevemos poemas e desenhamos solidões, estrategicamente. Porque brilhamos como os mil sóis de Maiakóvski e corremos como Criolo e armamos as constelações de Mallarmé em uma zona de educação pela pedra. Porque nos apartamos felizes com nossas pequenas rusgas para tantas zonas quanto nos forem possíveis abraçar. Porque pensar é agir em direção a um campo aberto por onde flutua o instinto de não ter teorias. Porque o artifício e o absurdo estão nas superfícies humanas tal qual a vida na amizade. Porque nos encontramos, sempre, onde o poético é uma lida criativa de luta. Porque é na zona que escrevemos que há muitos porquês.

\section{Referências}

AGAMBEN, Giorgio. O amigo. In: AGAMBEN, Giorgio. O que é o contemporâneo? e outros ensaios. Chapecó: Argos, 2009. p. 78-92.

AL ŸS, Francis. Sometimes doing something poetical can become political and sometimes doing something political can become poetical. Nova York: David Zwirner Gallery, 2007.

ANTUNES, A.; FROMER, M.; BRITTO, S. Comida. Música (3:57 min). In: ÁLBUM de estúdio de Titãs. Jesus não tem dentes no país dos banguelas. Rio de Janeiro: Gravadora WEA, 1987.

AQUINO, Julio Groppa. Da autoridade pedagógica à amizade intelectual: uma plataforma para o ethos docente. São Paulo: Cortez, 2014.

BARROS, Manoel de. Poesia completa. São Paulo: Leya, 2010.

BARTHES, Roland. O rumor da língua. São Paulo: Martins Fontes, 2004.

BARTHES, Roland. Sade, Fourier, Loyola. São Paulo: Martins Fontes, 2005.

BEY, Hakim. Zonas autônomas. Porto Alegre: Deriva, 2010.

BLANCHOT, Maurice. A conversa infinita: a palavra plural. São Paulo: Escuta, 2001. 
BLANCHOT, Maurice. A conversa infinita: a experiência limite. São Paulo: Escuta, 2007.

BLANCHOT, Maurice. L’Amitié. Paris: Gallimard, 2010.

BOURDIEU. Pierre. Homo academicus. Florianópolis: Ed. da UFSC, 2011.

BRISANT, Ni. Se eu tivesse meu próprio dicionário. São Paulo: Selin Trovoar, 2018.

CARNEIRO, Beatriz S. Arte: máquina de guerra. Verve, São Paulo, n. 11, p. 218-232, jan./jun. 2007. Disponível em: https://revistas.pucsp.br/index.php/verve/article/download/5189/3722. Acesso em: 5 out. 2020.

COMITÊ INVISÍVEL. Aos nossos amigos: crise e insurreição. São Paulo: n-1 edições, 2016.

COSTA, Cristiano Bedin da; MUNHOZ, Angélica Vier; LULKIN, Sergio (org.). Porque esperamos: notas sobre a docência, a obsolescência e o vírus. Porto Alegre: UFRGS, 2020.

COSTA, Luciano Bedin. AMORIM, Alexandre Sobral. Introdução à teoria das linhas para a cartografia. Atos de Pesquisa em Educação, Blumenau, v. 14, n. 3, p. 912-933, set./dez. 2019, p. 912-933. Disponível em: https://proxy.furb.br/ojs/index.php/atosdepesquisa/article/view/8045/4450. Acesso em: 18 fev. 2021.

DARDOT, Pierre; LAVAL, Christian. Comum: ensaio sobre a revolução no século XXI. São Paulo: Editora Boitempo, 2017.

DELEUZE, Gilles. Crítica e clínica. São Paulo: Editora 34, 1997.

DELEUZE, Gilles; GUATTARI, Felix. Prefácio Para Edição Italiana. In: DELEUZE, Gilles; GUATTARI, Felix. Mil Platôs: capitalismo e esquizofrenia. Rio de janeiro: Ed. 34, 1995. v. 1, p. 7-9.

DELEUZE, Gilles; GUATTARI, Felix. Devir-Intenso, Devir-Animal, Devir-Imperceptível. In:

DELEUZE, Gilles; GUATTARI, Felix. Mil Platôs: capitalismo e esquizofrenia. Rio de Janeiro: Editora 34, 1997b. v. 4, p. 11-113.

DELEUZE, Gilles; GUATTARI, Felix. Tratado de nomadologia: a máquina de guerra. In: DELEUZE, Gilles; GUATTARI, Felix. Mil Platôs: capitalismo e esquizofrenia. Rio de Janeiro: Editora 34, 1997a, p.11-110. v. 5.

FOSTER, Hall. O complexo arte-arquitetura. São Paulo: Ubu Editora, 2017.

HAN, Byung-Chul. Topologia da violência. Petrópolis: Vozes, 2017.

JACQUES, Paola B. (org). Apologia da deriva: escritos situacionistas sobre a cidade. Rio de Janeiro: Casa da Palavra, 2003.

MELO, Tarso de. Quando a delicadeza é uma afronta. In: CULT: antologia poética \#2. São Paulo: Revista Cult, 2019.

ORTEGA, Francisco. Por uma ética e uma política da amizade. Caderno de Leituras, Belo Horizonte, $\mathrm{n}$. 109, p. 1-17, jul. 2020. Disponível em: https://chaodafeira.com/wp-content/uploads/2020/07/cad109por uma etica e uma politica da amizade-francisco ortega.pdf. Acesso em: 30 set. 2020.

PRECIADO, Paul B. Aprendendo do vírus. São Paulo: Editora n-1, 2020. E-book.

QUATRO, Fred Zero; SCIENCE, Chico. Caranguejos com Cérebro. In: MANGUEBIZZ. O surgimento do Manguebeat. Rio de Janeiro: 21 nov. 2013. Disponível em: https://manguebizz.wordpress.com/2013/11/21/o-surgimento-do-manguebeat/. Acesso em: 4 out. 2020.

SAFATLE, Vladimir. O circuito dos afetos: corpos políticos, desamparo e o fim do indivíduo. São Paulo: Cosac Naify, 2016. 
SANT'ANNA JUNIOR, A. de. et al. (a senha é amor). In: MUNHOZ, A.; COSTA, C. B. da; LULKIN, S. (org.). Porque esperamos [notas sobre a docência, a obsolescência e o vírus]. Porto Alegre: UFRGS, 2020. p. 60-66. Disponível em:

http://www.bibliotecadigital.ufrgs.br/da.php?nrb=001115604\&loc $=2020 \& \mathrm{l}=678667 \mathrm{c} 8 \mathrm{fd} 761043$. Acesso em: 3 out. 2020 .

SARTRE, Jean Paul. Entre quatro paredes. Porto Alegre: Deriva, 2006.

SCRAMIM, Susana. HONESKO, Vinícius. Apresentação. In: AGAMBEN, Giorgio. O que é o contemporâneo? e outros ensaios. Chapecó: Argos, 2009. p. 9-22.

SIMONDON, Gilbert. A individuação à luz das noções de forma e de informação. Rio de Janeiro: Ed. 34, 2020.

TAVARES, Gonçalo. Atlas do corpo e da imaginação. Lisboa: Caminho, 2013.

VALÉRY, Paul. Variedades. São Paulo: Iluminuras, 2007.

ZOURABICHVILI, François. O vocabulário de Deleuze. Rio de Janeiro: Relume Dumará, 2004. 